\title{
Stem cells: source and therapeutic application
}

\author{
Haben FESSEHA ${ }^{\text {a }}$ \\ School of Veterinary Medicine, Wolaita Sodo University, P. O. Box 138, Wolaita Sodo, Ethiopia \\ Corresponding author's Email: tseyon.h@gmail.com; (D) ORCiD: 0000-0001-6516-3036
}

\section{ABSTRACT}

Introduction. Stem cells spontaneously renovate themselves into a specialized adult cell type. These defining characteristics have a lot of advantages in stem cell-based therapies. The two key types of stem cells are pluripotent and multipotent, which can differentiate to various cells in the adult body and only restricted cell types, respectively. Currently, Stem cell treatment is now very promising, bringing tremendous promise for medical medicine by offering treatments for untreatable disorders. Regulated laboratory steps of stem cell development and derivation are needed to ensure the genesis of stem cells. Besides, before implementation, stem cells should undergo quality control and teratoma development tests, which are necessary to determine their properties. While progress in the clinical use of stem cells is being made, there are still barriers to stem cell therapy being embraced internationally. Aim. The biology, cell sources, characteristics, differentiation, therapeutic application potential and manipulation achievement are discussed.

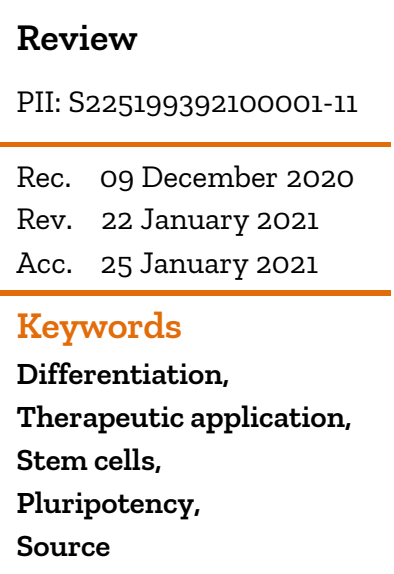

\section{INTRODUCTION}

Stem cells are cells that produce and accept all other specialized cells to be the raw materials of the body. A stem cell is basically a cell type that has a single capacity to convert or discern into any adult human tissue, either "starter" or "blank source." An adult human body has about 100 trillion stem cells. These potent and "undifferentiated cells" are present in any single multicellular organism on earth and can be replicated to more stable cells of the same form indefinitely by the cell differentiation process $[1,2]$. Stem cells are split into daughter cells, and after division with a more basic feature, such as blood cells, brain cells, heart muscle cells, or bone cells, these daughter cells either become new stem cells by self-renewal or become specialized cells. There is no other cell in the body than stem cells, which can create new cell types naturally $[3,4]$.

Stem cells can develop every tissue in the human body and can likely be used for the reconstruction or remediation of the tissue in the future. Stem cells are also called progenitor cells because they are capable of assuming the position and function of other cells. The key distinction between stem cells and progenitor cells is that the progenitor cells can separate themselves from one or more cells but cannot divide and replicate while the stem cells can forever $[5,6]$.

Stem cells must exhibit the following two essential characteristics. First, the progeny of stem cells must be precisely the same as the source cell. This characteristic is also valid for unregulated divisive cancer cells, while the division of stem cells is closely regulated. The additional criteria for stem cells must also be noted; they must be able to contribute to a specialized cell type that forms part of the healthy animal [7, 8]. Stem cells typically contain several different types of cells. Embryonic and adult stem cells are widely used to differentiate stem cells by their level of developmental stage. However, these terminologies don't fully describe the condition. Thus, a new study has demonstrated how to restore adult cells to the embryonic stems in the complete division and, on the other hand, to adult stem cells in a fetus, placenta, umbilical cord blood, and babies also known as somatic stem cells $[2,7,9]$.

Various researches are underway in order to establish different stem cell origins to cure neurodegenerative disorders, diabetes, and cardiovascular diseases $[3,7,10]$. The only therapy in hematopoietic stem cell transplantation (HSCT) had developed itself since 2016. The cells are usually transplanted into bone marrow, but the blood of the umbilical cord may also derive them [11]. HSCT has been used to treat patients with diseases such as leukemia and lymphoma for more than 30 years; it remains the most commonly practiced type of stem cell therapy [12]. During chemotherapy, most growing cells are killed by cytotoxic agents. Yet, leukemia or 
neoplastic cells cannot differentiate against the hematopoietic stem cells inside the bone marrow [13, 14]. During conventional chemotherapy, the stem-cell transplant attempts to reverse the condition that is considered as a potential side effect. The bone marrow of the donor reintroduces however functional stem cells to replace the missing cells in the body of the host in the process. The transplanted cells also generate an immune response that helps to kill off the cancer cells and this process can lead to serious side effects due to immune reaction between the graft and host disease $[2,15]$.

Stem cell treatment has been contentious after many developments such as scientists' ability to separate and grow embryonic stem cells and the use of methods to build inductive pluripotent stem cells and create stem cells by somatic nucleic transfer. Pluripotent stem cells in the body can be divided into multiple cell types. Also, pluripotent cells will gradually become any cell in the body by divided into multipotent stems, which are divided into much limited specialized cells themselves $[7,9]$.

Pluripotent stem cells in normal development only remain in the embryo for very brief periods until they are divided into the advanced multipotent stem cells, which ultimately create the body's specialized tissues. The more restricted multipotential stem cells come in different subtypes: some may only become cells with a certain germline (endoderm, mesoderm, ectoderms), while some may only become cells that have a certain tissue [9, 16].

A stem cell line is a colony of cells, all of which come from the original single stem cell developed in a laboratory. However, such cell types keep growing without differentiating into specialized cells and these clusters of cells can be resulting from the cell line. Ideally, stem cell lines will be free of genetic abnormalities, and more stem cells will be produced and frozen or exchanged with other researchers. Stem cell treatment is used to restore the tissues with or without stem cells or their variants that have been diseased, dysfunctional, or injured. This is the next chapter of organ transplants which uses only small quantities of cells instead of donor organs $[7,10,17]$.

Different researchers develop stem cells in a laboratory on their potential application for different human diseases. First, these stem cells may divide into various types of cells, such as heart muscle cells, blood cells, or nerve cells. It can then be introduced into an individual in the specialized cells. For instance, if the individual has heart failure, such types of cells could be inserted into the heart muscle. These healthy heart muscle cells transplanted will then help to restore damaged heart muscle [10, 18, 19]. Even though there is ongoing research on the potential use of stem cells, researchers have also demonstrated that adult bone marrow cells that are directed to become cardiac-like cells can rebuild cardiac tissue in humans. Thus, this is to review the biology, source, and therapeutic applications of stem cells.

\section{HISTORY OF STEM CELLS}

The term "stem cell" was first introduced around 1868 by German biologist Ernst Haeckel and he used it to characterize the fertilized egg event that will become a live breathing body. In 1908, Russian histologist Alexander A. Maximow proposed that the very presence of cells in our blood was considered hematopoietic stem cell. Later in 1924, It was the first to recognize mesenchyme within the form of a tissue cluster that is one cell precursor. The mesenchymal cells were then considered to divide into various blood cell types. Later, these cells are known as mesenchymal stem cells today [4, 10, 20].

In 1959, French oncologist Georges Mathé performed his first well-known bone marrow stem cell transplant. Five Yugoslav nuclear power personnel with substantial marrow injury after an accident conducted the experimentation process. Dr. Mathé was the founder of stem cell therapy for leukemia prevention of bone marrow transplants $[5,6]$.

The key origins of stem cells are bone marrow. In 1950s-1970s, Dr. E. Donnall Thomas at the Fred Hutchinson Cancer Research Center conducted stem cell therapeutics from Bone Marrow. The study by Dr. Thomas has demonstrated that the intravenously injected stem cell derived from the bone marrow will create new blood cells $[8,21]$. The initial use and study of stem cells began at the University of Mahidol, Thailand at the Medical Faculty of Siriraj, around 1995. Thailand's early pioneers in stem cell science focused mainly on thalassemia awareness and treatment, a prevalent form of blood disease in Thailand [3, 19].

Germ cells, the embryo, fetus, and adult are the potential sources for different kinds of stem cells and have shown a promising effect to cure various debilitating diseases through the provision of cell-replacement therapies known as regenerative medicine. Stem cell research gets considerable acceptance through mass media and generates a great deal of public interest; however, it raises many ethical and religious arguments. The embryonic stem cells have tremendous versatility as compared to adult stem cells. In order to prefer one cell, type over another, the biology of such cells has yet to be understood through research for future 
applications. Stem cell research opens-up the new field of 'cell-based therapies' and, as such, several safety measures have also to be evaluated $[19,20]$.

\section{STEM CELL TYPES}

Stem cells are unspecialized cells and different kinds of somatic cells in the human body have been described. It varies from single cells to more specialized cells, which form the base of the human organ or tissue. They can also distinguish between any organism cell and possess the capacity to renovate itself. Stem cells were present at various levels of specialization, both as embryos and adult cells. For each stage the developmental capacity is diminished, so a unipotent stem cell cannot divide into as many cell types as a pluripotent cell [22].

The key characteristics of stem cells are multipotency and self-renewal. Multipotency is the ability to divide between various cell types with a similar germ layer (endoderm, mesoderm, or ectoderm) whereas the ability to create identical copies through cell division is self-renewal. Stem cells have a large ability to proliferate and It may come from a vast variety of human tissues [23].

Mammalian stem cells are generally classified based on their tissue of origin. The ovary and testis are known as stem cells of the gonads since they contain oogonia and spermatogonia. In adult mammals, only the germ cells undergo meiosis to produce male and female gametes, which fuse to form the zygote that retains the ability to make a new organism thereby ensuring the continuation of the germline. In fact, the zygote is the most primitive cell that produces the first two cells by cleavage and these germ cells are known for this unique characteristic of developmental totipotency. Intriguingly, the Oct 4-an embryonic transcription factor critical for the maintenance of pluripotency-continues to be expressed in the germ cells but is absent in other peripheral tissues [20].

Mesenchymal stem cells can be categorized into multiple stem cell groups. Adult stem cells, for example, can make up cartilage, bone, tendon, ligament, muscle, skin, and nerve cells, whereas blood cells are the only origin for hematopoietic stem cell lines (red cells, white cells, and platelets), while neural stem cells originate from cells of the nervous system [21].

Embryonic stem cells (ESCs) originate from blastocysts during the division of the 16-cell stage. Pluripotent cells are cells that create all sorts of cells in the developing embryo. ESCs will supply cells for transplantation virtually infinite. Surprisingly, after in vivo transplant, ESCs form teratomas. Purification of neural cells is practicable by the elimination of pluripotent tumor cells, but the resultant populations of cells are likely to be no different from NSCs from other outlets [7, 23].

Totipotent stem cells may be specialized into cells of different structures. A zygote is a totipotent cell that has the greatest ability for distinguishing between cells and embryos. These cells may ultimately form a placental, or become one of the three layers of germ. The inner cell mass of the blastocyst comes pluripotent after about 4 days which is the foundation of pluripotent cells $[2,3,19]$.

Pluripotent stem cells (PSCs) are cells that specialize in germ layers in any type except placental structures which are extraembryonic. Inner cell mass in pre-implant embryos originates from the embryo stem cells (ESCs). Induced pluripotent stem cells (iPSCs) extracted from an epiblast layer of implanted embryos are another illustration. The pluripotency of these cells ranges from completely pluripotent cells including ESCs and iPSCs to less potency-multi-, oligo- or unipotent cells and their efficacy is evaluated through teratoma formation assay. Artificially produced from somatic cells, iPSCs act in a similar way to PSCs. Their cultivation and use for current and future regenerative medicine is very exciting $[8,24,25]$.

Multipotent stem cells are differentiated in contrast to PSCs into restricted cell types only but may be specialized in various cells with particular cell lines. For instance, blood cell hematopoietic stem cells may vary in different blood cell types. A hematopoietic stem cell is converted after transformation into an oligopolistic cell. However, its differentiation abilities become restricted to its own cells type only. Any multipotent cells, though, maybe transformed into unrelated cell types, indicating that they are called pluripotent cells [5, 26].

Oligopotent stem cells are stem cells that can be distinguished into just a few cell types, such as myeloid stem cells, but not red blood cells.

Unipotent stem cells, such as dermatocytes, are only capable of becoming one cell type. There are special kinds of stem cells that can break up twice, which makes them an outstanding therapeutic candidate in regenerative medicine but less diverse from other types of stem cells [2, 19, 24].

Neural stem cells (NSCs) In the adult human brain, they are located mostly in the subventricular and hippocampal regions. These cells are characterized by three groups of cerebral cells: neurons, astrocytes, and oligodendrocytes. NSCs can be derived from many central nervous system areas from exogenous sources and 
grown as neurospheres in vitro [23]. Neurosphere samples of real stem cells, dedicated progenitors, and segregated progenies are heterogeneous cell collections. NSCs may also be produced from embryonic or fetal brain tissue. Once spontaneously differentiated into serum-free media, they release oligodendrocytes, neurons, and astrocytes. In functional neuronal subtypes, such as cortical projection neurons, interneurons, and hippocampal pyramidal neurons, NSCs may differentiate $[27,28]$.

Umbilical cord blood is a viable alternative to transplantation of bone marrow and includes multiple stem cell types such as MSC and endothelial progenitor cells. Recently cord blood was isolated from pluripotent stem cells. The entire mononuclear blood fraction is readily collected from cord blood in various animal models to determine potential neuroprotective results. It includes all the cord blood stammers and all cord blood cells [20]. In vitro division of human umbilical cord blood mononuclear (HuCBCs) into nearly all adult cells and neuronal cells. Recently, iPSCs were developed from cord blood in some laboratories. The several benefits of HuCBCs include ready-to-use without harm to babies or mothers, minimal ethical concerns, low immunogenicity, and in vivo benefits in animal diseases. Often a promising source of reconstruction therapy is a connective tissue of a cord (Whartonjelly) that produces comparatively large amounts of MSCs that are more proliferating than bone marrow [29, 30].

Induced pluripotent stem cells (iPSCs) can be obtained by nuclear reprogramming by inducing terminally distinct somatic cells. Reprogramming of retroviral vectors with four genes (Oct3/4, Sox2, c-Myc, and Klf4) containing cDNA was accomplished by translating the mouse or human blasts. Recently, a related finding was achieved by transducing fibroblasts using the proto-oncogene c-Mycs Oct4, Sox 2, NANOG, and LIN28. The ability to build cellular products for autologous grafts is an advantage of iPSCs. There is therefore no graftversus-host approach to the management of iPSC-derived progenitors [23]. Recent research found that adult somatic cell mice could develop functional neurons of which a small proportion also expressed GABAergic markers without intermediate iPSC. It is noteworthy because the same mechanism is formed in humans, allowing hematopoietic progenitors and adult cells for the first time directly to be derived from human dermal fibrotic products without pluripotency. This approach is ethically appropriate and reduces the possibility of tumor development potentially [8].

\section{STEM CELL BIOLOGY}

A sperm and ovum fertilization fuse is developed and its inside wall is bordered by short-lived stalk cells, i.e., embryonic stem cells. Blastocysts comprise two distinct types of cells: the inner cell mass (ICM), which differentiate into epiblasts and encourages the growth of a fetus, and the trophectoderm (TE). The ICM microenvironment is dominated by blastocysts. TE helps to grow and develop the extraembryonic support systems required for the embryo's successful origin, such as the placenta. The ICM cells remain indistinguishable, fully pluripotent, and proliferative since TE begins to form a specialized support system [19, 31]. Stem cells can form various kinds of cells within an organism due to their pluripotency. The ICM extracts human embryonic stem cells (hESC). The cell type aggregations called germ layers: endoderm, mesoderm, and ectoderm in the course of embryogenesis, which ultimately contributes to the differentiated cells and tissues of the fetus and later the adult body. After hESCs distinguish themselves into one of the germ layers, they become multipotent stem cells with only the potential of the germ layer cells [32].

In any portion of an organism, pluripotent stem cells are found as undifferentiated cells and it can be consecutive stem cell generations by proliferation and then in some physiological circumstances, it may divide into specialized cells. The stem cell specialization process is regulated by internal and external signals. During external signaling, direct physical interaction occurs through the tissue around cells or chemical secretion, while internal signals are mediated by DNA genes [33].

Stem cells also engage in internal body repair processes. New cells are replenished and created unlimited when an organism is alive. The activity of stem cells mainly relies on the organ they are constituted. For instance, there is a continuous and constant division of cells in bone marrow, whereas, in organs like the pancreas, the distinction is only under special circumstances of physiology [19, 34].

\section{SOURCES OF STEM CELLS}

Autologous and Allogeneic cells are the two stem cell types used in recent years in research and therapy. Autologous means when it is transplanted from the patient's own body whereas Allogeneic means that an individual other than the recipient donates stem cells. The common feasible sources of autologous stem cells 
are human bone marrow, peripheral blood dental pulp, and fat-derived or adipose stem cells [4, 10]. Besides, the patient does not receive allogenic derived stem cells themselves and they are mostly acquired from the patient's stem cell bank, which contains donated umbilical cord tissue, human placenta (Wharton's jelly), or bone marrow from the immediate family of the patient. These cells balance the patient with HLA to reduce the risk of damage to the host disease [35].

Scientists have identified a variety of stem cell origins. Among these, the embryos being used in embryonic stem cell research come from eggs that were fertilized at in vitro fertilization clinics but never implanted in a woman's uterus. The stem cells are collected from donors after getting full consent. In laboratory test pipes or Petri dishes, the stem cells can live and grow in special solutions [11]. Embryonic stem cells are derived from an embryo of 3-5 days old and it is called blastocyst since it has about 150 cells. These stem cells are pluripotent and can be split into more stem cells or some sort of cell in the body. This flexibility allows for the regeneration and restoration of tissues and organs by embryonic stem cells [17, 32].

In most human tissues, adult stem cells such as bone marrow and fat are present in limited amounts. In contrast to ESCs, adult stem cells are differentiated to only limited and identical forms of cells. For instance, researchers previously thought that the stem cells of the bone marrow will only generate blood cells, but they may now differentiate into bone or heart muscle cells. Moreover, emerging research indicates that adult stem cells may contain different cell types. For instance, in people with neurological or heart disease, adult stem cells are being studied $[3,10,20]$.

Adult cells with the characteristics of embryonic stem cells have been modified (induced pluripotent stem cells). Standard adult cells have been converted into stem cells successfully through genetic reprogramming. Researchers will reprogram cells in order to behave like embryonic stem cells by modifying the genes in adult cells. This new approach will allow researchers to use reprogrammed cells instead of embryonic stem cells and avoid the rejection of new stem cells by the immune system. However, scientists don't yet know whether using altered adult cells will cause adverse effects in humans [9, 20] (Figure 1).

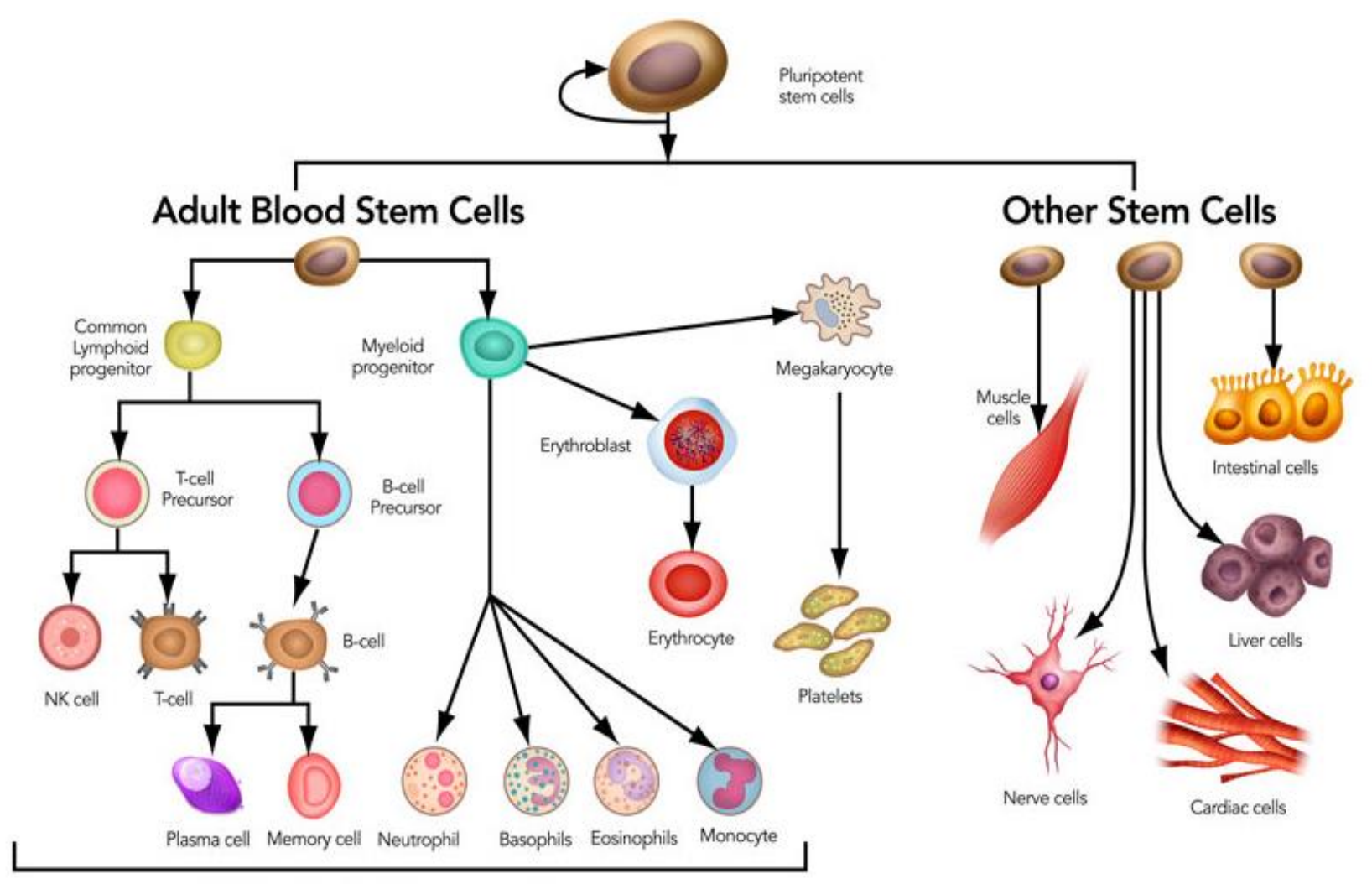

\section{Cells of the Immune System}

Figure 1. Different sources of stem cells. Source: Stem cell immune regenerative.com

\section{Comparison of embryonic versus adult stem cells}

Embryonic stem cells are collected from the early-stage embryo forming cells in a clinic for in vitro fertilization while female eggs are fertilized with a man's sperm. The National Institutes of Health in 2009 introduced the recommendations for human stem cell studies. The guidelines define the use of embryonic stem 
cells for ethical study and provide recommendations for the donation of embryonic stem cells. The guidelines describe embryonic stem cells from in vitro fertilization embryos should only be used if the embryo has been discontinued [36]. Embryonic stem cells can specialize into several kinds of cells abnormally. Thus, researchers are investigating a mechanism to control this spontaneous growth and differentiation of embryonic stem cells. Embryonic stem cells might also trigger an immune response in which the recipient's body attacks the stem cells as foreign invaders or the stem cells might simply fail to function normally, with unknown consequences. Scientists remain to investigate how these potential problems can be prevented [7, 20]. As compared to embryonic stem cells, adult stem cells are not flexible and resilient and cannot be manipulated to generate any cell type that restricts the treatment of diseases by ASCs. Besides, ASCs are often more likely to produce environmental threat defects such as toxins, or cell replication errors. Yet, researchers found that adult stem cells are more adaptable than was initially believed [8].

Table 1. Differences between adult stem cells (hASCs) and embryonic stem cells (hESCs).

\begin{tabular}{|c|c|c|}
\hline Variable & Adult stem cells & Embryonic Stem Cells \\
\hline Source of stem cell & $\begin{array}{l}\text { Stem cells from organs are scarce and } \\
\text { hard to access and purify }\end{array}$ & $\begin{array}{l}\text { Once derived and propagated, stem cells exhibit } \\
\text { prolific cell growth and are abundant }\end{array}$ \\
\hline Cell-line & No cell-lines available & $\begin{array}{l}\text { Cell-lines available; easy to scale-up using bulk culture } \\
\text { protocol }\end{array}$ \\
\hline Stem cell potency & Multipotent; plasticity narrow & Pluripotent; versatile and plasticity wide \\
\hline Tissue Compatibility & $\begin{array}{l}\text { Maintenance of normal genetic make- } \\
\text { up in vitro not known }\end{array}$ & $\begin{array}{l}\text { Normal karyotype in late passages in 'cut and paste' } \\
\text { protocol; changes in karyotype in the late passage in } \\
\text { high-density bulk culture protocol }\end{array}$ \\
\hline Level of Telomerase & Telomerase levels low & $\begin{array}{l}\text { Telomerase levels high and consistent; unlimited self- } \\
\text { renewal of cells }\end{array}$ \\
\hline Chromosome length & $\begin{array}{l}\text { Shortening of chromosome length with } \\
\text { aging }\end{array}$ & $\begin{array}{l}\text { No shortening of chromosome length with serial } \\
\text { passaging }\end{array}$ \\
\hline \multirow[t]{2}{*}{ Apoptosis } & Early apoptosis & Late apoptosis \\
\hline & $\begin{array}{l}\text { Customizing stem cells/differentiated } \\
\text { tissues not possible }\end{array}$ & Possible via somatic cell nuclear transfer \\
\hline Teratogenicity & $\begin{array}{l}\text { No risk of teratoma induction after } \\
\text { accidental transplantation }\end{array}$ & $\begin{array}{l}\text { Risk of teratoma induction after transplantation if not } \\
\text { purified }\end{array}$ \\
\hline Reversing capacity & $\begin{array}{l}\text { Epigenetic genomic changes difficult to } \\
\text { reverse }\end{array}$ & Reversible \\
\hline Ethical Issue & No ethical issues & $\begin{array}{l}\text { Ethical issues limited to some countries and } \\
\text { institutions }\end{array}$ \\
\hline Application & Transplantation therapy & $\begin{array}{ll}\circ & \text { Transplantation therapy; } \\
\circ & \text { Pharmaceutical screening; } \\
\circ & \text { Gamete and embryo production; } \\
\circ & \text { Studies on human development, congenital } \\
& \text { anomalies, and infant cancers }\end{array}$ \\
\hline
\end{tabular}

Source: [20]

\section{MECHANISM OF ACTION}

Stem cells have the capability to treat several diseases. Coaxing stem cells can develop a single cell type and This is one of the biggest obstacles of any procedure dependent on stem cells. All stem cells can progress to another cell type through differentiation. When an investigator gets a mature cell type in a lab, the next move is to figure out how the cells will operate in the body. When a scientist has a mature type of cell in a laboratory tray, the next step is to see how these cells function in the body. Researchers must therefore recognize that the cells can be absorbed in and discarded by the body into the surrounding tissue [32]. The stem cells pass through a series of laboratory procedures before use for human purposes. For this purpose, the cells are first tested in a model of an animal that imitates man to evaluate the efficacy of the transplanted cells in treating the disease. Thus, such experiments are important since they can recover those functions that also will significantly benefit patients, while cells do not cure the disease entirely. Both of these potential findings must be tested by scientists. Researchers have to examine each of these possible outcomes [10]. 
Checking the cells in an animal model frequently does not provide adequate details. Many animal disease models do not replicate human disease exactly. For instance, a mouse with the same mutation that causes cystic fibrosis does not exhibit the same symptoms as a diseased human. Thus, stem cell treatment that addresses this cystic fibrosis mouse model may not be effective in humans. This is why researchers also have to examine the cells in many animal models [5,37]. Accordingly, the FDA for use in human research should allow stem cells grown in good manufacturing (GMP) conditions. According to GMP protocols, each cell group can expand in an equal, repeatable, and sterile environment during cell line production. This guarantees that each cell batch has the same properties and that the treatment of each person undergoing stem cell therapy is comparable [4].

Stem cell results could include attenuating the inflammatory reaction, choosing numerous factors that facilitate survival and enhancing plastic response in host tissue weakened, and restoring the synaptic transmissions through local reinnervation and/or promotion. Increased repair from these non-standard results is due to the exceptional in vivo stem cell capacity to discover the best route to such positive niches, where they live and function through associations with different cell types in the micro-environment $[23,38]$.

This association is mostly associated with integrins, which are proteins that work by internal and external signaling to regulate several cell functions, including survival, division, migration, and adherence. The complex expression of integrin shown by stem cells from multiple tissue contexts and the importance of integrated signage and addiction during development illustrate the need to understand the pathways for signaling [39].

Recently, specific surfaces have been established to derive, sustain, proliferate, and distinguish stem cells. These surfaces emulate the dynamic cell ecosystem that occurs in vivo to fit the conditions for tissue culture to each stem cell line and is ideal for clinical applications. While after transplantation stem cells will survive, the long-term cell survival does not seem sufficient to boost the outcomes. A recent study reveals a progressive reduction of intracranial applied MSCs although they continue over time in regenerative effects [23].

Graft stem cells contribute to the activation and global decrease of endogenous stem cell parts. While all these mechanisms are identified, they may differ in various animal models from the mechanisms behind the benefits of stem cell treatment. It should be noted that most studies have not shown any significant changes in anatomy and behavior following stem cell transplantation [40]. Nevertheless, MSC transplantation led to the recovery of the sensorimotor function; proliferation and differentiation into neurons, astrocyte, and oligodendrocytes; and re-wiring of the corticospinal tract in studies using bone marrow-derivative MSCs from a hypoxia and ischemia mice model [33].

\section{RISK FACTORS OF STEM CELL THERAPY}

The therapeutic application of stem cells depends on different risk factors. A risk is defined as a combination of the probability of occurrence of harm and the severity of that harm $[36,41]$. The type of stem cells used, their procurement, and culturing history, the level of manipulation, and the site of injection are among the risk factors that affect the outcome of stem cell therapy. Because of the variety of risk factors, the risks associated with different stem cell-based medicinal products may differ widely as well [41, 42].

All identified risks, such as risks or adverse events recognized during the clinical experience, and potential or hypothetical risks should be evaluated for an adequate benefit/risk assessment of a stem cell-based medicinal product [43]. Such an evaluation at the start and during the development of a stem cell-based therapy may help to determine the extent and focus of the product development and safety evaluation plans. Here we discuss several risks associated with stem cell-based medicinal products, and the risk factors contributing to these risks [20].

Different categories of risk factors can be distinguished. Firstly, risk factors associated with the intrinsic cellular properties of a particular cell type or class of stem cells; secondly extrinsic risk factors introduced by procurement, handling, culturing, or storage of the cells; and finally, the risk factors associated with the clinical characteristics (e.g. surgical procedures, immunosuppression, site, and mode of administration, or comorbidities) will be discussed. It is important to realize that multiple risk factors from these different categories can contribute to the risk to the patient $[15,30]$.

In general, different risk factors affect the application of stem cell-based therapies. The knowledge of these existing and other potential risk factors helps when new stem cell-based therapies are used. The first potential risk of stem cell therapy is tumor formation and multiple factors may contribute to tumor formation. Secondly, immune responses are the risks associated with, particularly for allogeneic stem cell transplantation. Third is the risk of human pathogen transmission and adventitious agents. Finally, there may be potential other risk factors with yet unknown risks to patients [44]. 
Like any transplanted organ, transplanted stem cells may be identified as alien and then discarded by the immune system. People continue to be immune-suppressive medications during their lifespan in transplants like the liver, the kidney, or the heart to stop the immune system from detecting and killing the organ alien. The risk of a rejection of an embryonic stem-cell tissue transplant by the immune system depends on its origin. The in vitro (IVF) embryo isolated stem cells shall have a genetic make-up that is not the same for the transplant recipient because the transplanted tissue is resisted by the recipient's immune system and a recipient must undergo a strong immuno-suppressive medicine. The same happens to an adult donor's stem cells [14, 36, 41].

On the other hand, SCNT or iPS cell science produced stem cells are perfectly hereditary. The immune system may overlook the transplanted cells, which they perceive as a natural body component. Some say that certain cell types cannot fully avoid the immune system notice, although the cell fits perfectly. For example, the genetic make-up for cancer cells is the same as those around the tissue so the immune system also detects and kills early tumors. It would be difficult to decide whether transplanted patient-specific cells will draw the interest of the immune system before more evidence is available from animal trials [24, 32].

While stem cells seem to be an ideal option for medicine, many problems do exist in the future. An ethical problem is one of the first ones. ESCs are the most common pluripotential stem cells. Legal issues still emerge from treatments related to their use. The explanation for this began when researchers in 1998 found out how ESCs can be separated from human embryos [30].

While HESCs are used for tissue regeneration therapeutic purposes, the sources and source of the cells are still ethically questioned. Owing to the complexities of stem cell management mechanisms, in vitro observations also have a great deal to understand. Tumor risk must be measured for stem cells to become readily available and popular therapy. The second issue is effective immunosuppression between the stem cells and the body of the patient. At the moment one of the better ideas is to use the cells of the patient to turn them into their pluripotent developmental stage $[5,45]$.

The new stem cells should have to completely replace the damaged or malfunctioning natural cells. There is also uncertainty about the ability to acquire stem cells for either the recipient or the donor without risk of illness or suffering. Besides, before being included in a broad range of regenerative therapies on live patients unregulated proliferation and cell differentiation must be tested after application [24].

One of the reasons restricting the use of iPSCs is their notorious tumorigenic function. Oncogenes can increase their expression when cells are reprogrammed. A technique was found to allow oncogenes to be extracted from a cell after pluripotency has been reached, but this is still not successful and takes a longer time in 2008. Deletion of the tumor suppressor géne p53 can improve the reprogramming process but this gene is also a key cancer regulator that prevents further mutation in the reprogramed cells. It is therefore difficult to eliminate this gene. Another challenge, which is increasingly being reduced each year is the low productivity of the operation $[11,19]$.

Embryonic stem cells pledge to shape every cell in the body. The concern is that they do this in the shape of teratomas when injected into an animal. These tumors are masses of many kinds of cells which can include hair cells and several other tissues. These teratomas are one reason why embryonic stem cells need to maturate into extremely cleansed adult cell forms before they are inserted in humans. Virtually all research has demonstrated that mature cells do not tend to return to a teratoma-forming cell but only to their unique identity $[10,17,24]$.

\section{APPLICATION OF STEM CELLS}

Stem cell transplant is the most important thing in the application of stem cells for treating different diseases. Stem cells are first specialized into the adult cell form required to repair tissue weakened by disease or injury in a stem cell transplant. For this purpose, the cells must have Self-renewal capability. The ability of a cell to undergo several cycles of regular cell division while retaining an undifferentiated condition is defined as selfrenewal. The cells should be potent to separate mesoderms or ectoderms into three germ layers [25].

Stem cells are used as a substitute for injured nerves due to spinal cord injury, stroke, Alzheimer's disease, Parkinson's disease, etc. Furthermore, they may manufacture insulin to help people with diabetes or cartilage to restore arthritis-related damage; or replace almost any damaged or ill tissue or organ $[19,23]$. For instance, the key candidates for HESC-based cell substitution therapy include Type 1 diabetes and parkinsonism. The success of the Edmonton protocol and cadaver islet transplantation augur well for the success of an analogous strategy 
using hESC-derived islet progenitor cells. A related approach to the treatment of Parkinson's disease using hESC-derived dopaminergic neural can be used [20].

Recently, in the course of clinical trials, there is an increasing range of possible therapies that have been approved until now by the FDA only a few stem cell therapies. Fedratinib was the first-line myelofibrosis drug authorized by the FDA in August 2019 (scarring of the bone marrow). The first stem cells to be detected and applied in the clinic were stem cells in the bone marrow. It has helped thousands of patients globally with blood cancer like leukemia to save lives [11].

Recently, stem cells derived from the bone marrow are used for the treatments of various kinds of cancer cells. Moreover, according to different research outputs, bone marrow transplants showed a promising effect in medicating autoimmune diseases and minimize the risk of rejection of the transplanted organs. Researchers continue to focus on all cell types to recognize their ability for breakthroughs in different diseases $[8,19,25]$.

\section{Stem cells in Treatment of Osteoarthritis}

Osteoarthritis is an active, inflammatory, progressive, and degenerative disorder that remains the main cause of pain and disability in an aging population across the world. There is still a lack of effective pharmaceutical therapies that modify the disease progression since all currently available therapies are aimed at minimizing symptoms rather than disease prevention. Current conservative management strategies fail to alter disease progression and even surgical options including joint replacement have some significant complications. Moreover, the burden of musculoskeletal disease is progressively expanding and highlights the need for both preventative and reparative therapies rather than commonly accepted pain management interventions [46]. According to a systematic review of clinical trials, mesenchymal stem cell-based cell therapies shows a promising effect in the treatment of knee osteoarthritis (through regrowth of cartilage volume) and importantly show promise in disease modification, with potential inhibition of progression and recent evidence of reversal of this degenerative process. Besides, clinical trials have indicated a relative safety in both intravascular and intra-articular injections $[46,47]$.

\section{Incurable neurodegenerative disease therapy}

The emergence of incurable neurodegenerative disorders including Parkinson's disease, Alzheimer's (AD), and Huntington's disease can be slowed down by stem cell treatment but, most significantly, the root of the issue can also be eradicated. Neuroscience has overruled the previous belief that adult neurosciences were not neurogenesis with the discovery of neural stem cells (NSCs) [10, 11, 32]. Moreover, Stroke is a public-health risk. However, thrombolysis remains the only accepted therapy for stroke till now. The bulk of preclinical trials and experimental research using stem cell therapy have shown very encouraging proof of benefits [48]. In preclinical mouse models of $\mathrm{AD}$, neural stem cells can boost cognitive ability [28]. Parkinson's neuronal degeneration (PD) is focal and hESCs are effective in generating neurons with dopaminergic effect [49]. PD is the right cell therapy disorder for iPSC. This treatment, however, remains in an experimental stage [18]. Aborted fetal brain tissue was used in Parkinson's disease patients. While the results were not consistent, they highlighted the importance and viability of treatments using pure stem cells [12].

\section{Neurorestorative therapies}

After neuroprotection (acute) therapies have failed, and scarring, inflammation, and edema have installed, the approach must be shifted then to a neurorestorative therapy rather than on preventing the extension of damage that has already been well established. This type of therapy focuses on orchestrating through all types of parenchymal cells (i.e. neuroblasts, immune cells, astrocytes, oligodendrocytes, and neurons), the enhancement of endogenous neurogenesis, angiogenesis, axonal sprouting, and synaptogenesis in affected brain tissue [12]. Neurorestorative procedures contain but are not restricted, stem cells. Pharmacological studies and other therapies such as electro-magnetic stimulation, device-based interventions, repetitive exercise, and task-oriented strategies are still underway. The combination of functional reorientation and adaptation following a stroke could be exploited for regeneration. Currently, certain forms of effectiveness have only been shown through limited treatment [50].

\section{Usage of dental stem cells}

Teeth have a complicated systemic structure and remain a highly demanding regenerative medicine content. Since they function in aspects such as jointing, chewing, or esthetics, their intricate nature makes 
them impossible to regenerate. The tooth is an invasive natural stem cell center. But, without stem cell utilization, either growing factors, grafts, or surgery are used to cure the most common periodontic diseases. Currently, Stem cells have been more commonly used than synthetic materials [29, 51]. There are, for example, stem cells that can differentiate into osteoblasts or cementoblasts in the periodontal ligament, and their functions were also measured in neural cells [52]. The technique of tissue engineering with stem cells is an effective way to treat periodontal diseases, particularly periodontal ligaments. Gene therapy using adenoviruscontaining growth factors is one of the alternative approaches for tissue techniques in periodontology [53]. Dentine regeneration is an effective process that leads to the creation of dentine bridges following animal studies [54]. Enamel is tougher than dentine to regenerate. The first is lost and reparation is unlikely after the division of the ameloblastoma cells in the enamel. Medical trials have successfully differentiated the ameloblastoma of bone marrow stem cells [55]. However, a significant proportion of stem cells in healthy dental tissue may decline if the dental tissue becomes both traumatized and inflamed. Besides, multiple classes may be isolated from dental stem cells $[19,56]$.

\section{STEM CELL TREATMENT AND ITS FUTURES PERSPECTIVE}

In order to be both ethical and safe, groundbreaking science and medical advances must still be closely controlled. Stem cell therapy is needed since it also has a profound effect on certain facets of life. Several challenges currently remain with respect to stem cells. The function of stem cell treatment in animal models is not completely known and this remains uncertain and this procedure shouldn't be missed. Fear of the unexpected is the biggest obstacle for the wide-ranging global adoption of the technique [26].

In order for stem cell-driven differentiation to be more effective and trustworthy to a normal user, efficacy must be strengthened. Another difficulty is the size of the operation. These challenges have a great effect on the future development of stem cell therapies. The development of millions of functioning and biologically exact cooperating cells will be necessary for the transplantation of new, completely functioning organs made from stem cell therapy. The generalization of these complex techniques would entail interdisciplinary and international cooperation [19]. The right recognition and separation of stem cells from the tissues of a patient and rejection due to immunological reaction by the recipients during stem cell transplantation are also another challenge of stem cell therapy. The immune system may perceive transplanted cells as foreign bodies, inducing an immune response resulting in transplantation or cell refusing, in some forms of stem cells and processes [6].

One suggestion that can "failsafe" stem cells is to apply an alternative to self-destruct if they become risky. Further production and durability of stem cells may contribute to a reduction of medical costs for people with incurable diseases at present. Instead of being treated extraordinarily costly, the patient may use stem cell therapy in the event of such organ failures. The consequence of an effective surgery would be immediate, and chronic pharmacological therapy and its needless side effects would be eliminated. Stem cell therapy is showing great progress and is used to treat several ailments and conditions even though stem cell science is facing different overwhelming challenges. They seem to have a huge influence on future medicine $[44,45]$.

\section{CONCLUSION}

Stem cells are potent "blank" cells that form the base of any organ, tissue, and cell in the human body. It is necessary because they are the only natural way to restore or rebuild permanently our weakened tissues and organs. Stem cell therapy is a promising scientific advancement that contributes a lot to the field of medicine. The ability of stem cells increases with each trial, however, several barriers remain to be eliminated. Firstly, more human-powerful and multipotential cell research is required as stem cell biology varies from animal and human models. Second, to prevent cancer development, it is important to properly grasp the common trait of unrestricted cell division shared between cancer cells and pluripotent stem cells. Third, at the required point of differentiation, there should be good knowledge regarding the acquisition of vast numbers of cells. Fourth, to increase cell development, longevity, and integration, systematic and precise protocols must be created. Finally, the efficacy and feasibility of stem cell therapy must be assured by clinical testing. Accordingly, untreatable neurodegenerative disorders can be treated with stem-cell treatment. This provides a great opportunity to sustain and prolong the quality of human life than ever before.

\section{Competing interests}

The authors declare that they have no competing interests. 


\section{REFERENCES}

1. Asahara T, Kalka C and Isner J. Stem cell therapy and gene transfer for regeneration. Gene therapy. 2000; 7 (6): $451-457$. DOI: https://doi.org/10.1038/sj.gt.3301142 Google Scholar

2. Hemmat S, Lieberman DM and Most SP. An introduction to stem cell biology. Facial plastic surgery. 2010; 26 (05): 343-349. DOI: https://doi.org/10.1055/s-0030-1265015 Google Scholar

3. Alison MR, Poulsom R, Forbes S and Wright NA. An introduction to stem cells. The Journal of Pathology: A Journal of the Pathological Society of Great Britain and Ireland. 2002; 197 (4): 419-423. DOI: https://doi.org/10.1002/path.1187 Google Scholar

4. Molofsky AV, Pardal R and Morrison SJ. Diverse mechanisms regulate stem cell self-renewal. Current opinion in cell biology. $2004 ; 16$ (6): 700-707. DOI: https://doi.org/10.1016/j.ceb.2004.09.004 Google Scholar

5. Nadig RR. Stem cell therapy-hype or hope? A review. Journal of conservative dentistry: JCD. 2009; 12 (4): 131. DOI: https://dx.doi.org/10.4103\%2F0972-0707.58329 Google Scholar

6. Strauer BE and Kornowski R. Stem cell therapy in perspective. Circulation. 2003; 107 (7): 929-934. DOI: https://doi.org/10.1161/o1.CIR.0000057525.13182.24 Google Scholar

7. Brignier AC and Gewirtz AM. Embryonic and adult stem cell therapy. Journal of Allergy and Clinical Immunology. 2010; 125 (2): S336S344. DOI: https://doi.org/10.1016/j.jaci.2009.09.032 Google Scholar

8. Kolkundkar U, Gottipamula S and Majumdar A. Cell therapy manufacturing and quality control: Current process and regulatory challenges. J Stem Cell Res Ther. 2014; 4 (9): 1000230. DOI: https://doi.org/10.4172/2157-7633.1000230 Google Scholar

9. Biehl JK and Russell B. Introduction to stem cell therapy. The Journal of cardiovascular nursing. $2009 ; 24$ (2): 98. https://dx.doi.org/10.1097\%2FJCN.0bo13e318197a6a5 Google Scholar

10. Mahla RS. Stem cells applications in regenerative medicine and disease therapeutics. International journal of cell biology. $2016 ; 2016$. https://doi.org/10.1155/2016/6940283 Google Scholar

11. Müller AM, Huppertz S and Henschler R. Hematopoietic stem cells in regenerative medicine: Astray or on the path? Transfusion Medicine and Hemotherapy. 2016; 43 (4): 247-254. https://doi.org/10.1159/000447748 Google Scholar

12. Lyon L. Stem cell therapies in neurology: The good, the bad and the unknown. Brain. 2018; 141 (10): e77-e77. https://doi.org/10.1093/brain/awy221 Google Scholar

13. Diekman BO and Guilak F. Stem cell-based therapies for osteoarthritis: Challenges and opportunities. Current opinion in rheumatology. 2013; 25 (1): 119. https://dx.doi.org/10.1097\%2FBOR.ob013e32835aa28d Google Scholar

14. Edwards R. Ivf and the history of stem cells. Nature. 2001; 413 (6854): 349-351. https://doi.org/10.1038/35096649 Google Scholar

15. Karanes C, Nelson GO, Chitphakdithai P, Agura E, Ballen KK, et al. Twenty years of unrelated donor hematopoietic cell transplantation for adult recipients facilitated by the national marrow donor program. Secondary title: Elsevier; 2008. https://doi.org/10.1016/j.bbmt.2008.06.006 Google Scholar

16. Bajada S, Mazakova I, Richardson JB and Ashammakhi N. Updates on stem cells and their applications in regenerative medicine. Journal of tissue engineering and regenerative medicine. 2008; 2 (4): 169-183. https://doi.org/10.1002/term.83 Google Scholar

17. Henningson Jr CT, Stanislaus MA and Gewirtz AM. Embryonic and adult stem cell therapy. Journal of Allergy and Clinical Immunology. 2003; 111 (2): S745-S753. https://doi.org/10.1067/mai.2003.133 Google Scholar

18. Kim SU and De Vellis J. Stem cell-based cell therapy in neurological diseases: A review. Journal of neuroscience research. $2009 ; 87$ (10): 2183-2200. https://doi.org/10.1002/jnr.22054 Google Scholar

19. Zakrzewski W, Dobrzyński M, Szymonowicz M and Rybak Z. Stem cells: Past, present, and future. Stem cell research \& therapy. 2019; 10 (1): 1-22. https://doi.org/10.1186/s13287-019-1165-5 Google Scholar

20. Bongso A and Richards M. History and perspective of stem cell research. Best practice \& research Clinical obstetrics \& gynaecology. 2004; 18 (6): 827-842. https://doi.org/10.1016/j.bpobgyn.2004.09.002 Google Scholar

21. Bianco P, Robey PG and Simmons PJ. Mesenchymal stem cells: Revisiting history, concepts, and assays. Cell stem cell. 2008; 2 (4): 313319. https://doi.org/10.1016/j.stem.2008.03.002 Google Scholar

22. Velasco RP, Myint CY, Khampang R, Tantivess S and Teerawattananon Y. Advanced health biotechnologies in thailand: Redefining policy directions. Journal of translational medicine. 2013; 11 (1): 1-9. https://doi.org/10.1186/1479-5876-11-1 Google Scholar

23. Titomanlio L, Kavelaars A, Dalous J, Mani S, El Ghouzzi V, et al. Stem cell therapy for neonatal brain injury: Perspectives and challenges. Annals of neurology. 2011; 70 (5): 698-712. https://doi.org/10.1002/ana.22518 Google Scholar

24. Hentze H, Graichen R and Colman A. Cell therapy and the safety of embryonic stem cell-derived grafts. Trends in biotechnology. 2007; 25 (1): 24-32. https://doi.org/10.1016/j.tibtech.2006.10.010 Google Scholar

25. Yamanaka S, Li J, Kania G, Elliott S, Wersto RP, et al. Pluripotency of embryonic stem cells. Cell and tissue research. $2008 ; 331$ (1): 5-22. https://doi.org/10.1007/s00441-007-0520-5 Google Scholar

26. NIH. National institutes of health resource for stem cell research. [july 21, 2008] the stem cell information stem cell basics page. Available at: $\mathrm{Http}$ ///stemcells.Nih.Gov/info/basics/ defaultpage.Asp. 2008.

27. Bhasin A, Srivastava MP, Mohanty S, Bhatia R, Kumaran SS, et al. Stem cell therapy: A clinical trial of stroke. Clinical neurology and neurosurgery. 2013; 115 (7): 1003-1008. https://doi.org/10.1016/j.clineuro.2012.10.015 Google Scholar

28. Castillo-Melendez M, Yawno T, Jenkin G and Miller SL. Stem cell therapy to protect and repair the developing brain: A review of mechanisms of action of cord blood and amnion epithelial derived cells. Frontiers in neuroscience. 2013; 7: 194. https://doi.org/10.3389/fnins.2013.00194 Google Scholar

29. Lin NH, Gronthos S and Bartold P. Stem cells and periodontal regeneration. Australian dental journal. 2008; 53 (2): 108-121. https://doi.org/10.1111/j.1834-7819.2008.00019.x Google Scholar

30. McKee C and Chaudhry GR. Advances and challenges in stem cell culture. Colloids and Surfaces B: Biointerfaces. 2017; 159: 62-77. https://doi.org/10.1016/j.colsurfb.2017.07.051 Google Scholar

31. Chiba S. Concise review: Notch signaling in stem cell systems. Stem cells. 2006; 24 (11): $2437-2447$. https://doi.org/10.1634/stemcells.2005-0661 Google Scholar 
32. Little $\mathrm{M}-\mathrm{T}$ and Storb R. History of haematopoietic stem-cell transplantation. Nature Reviews Cancer. $2002 ; 2$ (3): $231-238$. https://doi.org/10.1038/nrc748 Google Scholar

33. Larijani B, NASLI EE, Amini P, Nikbin B, Alimoghaddam K, et al. Stem cell therapy in treatment of different diseases. 2012 . 50(2): 79-96. https://www.sid.ir/en/journal/ViewPaper.aspx?id=233720 Google Scholar

34. Sukoyan MA, Vatolin SY, Golubitsa AN, Zhelezova AI, Semenova LA, et al. Embryonic stem cells derived from morulae, inner cell mass, and blastocysts of mink: Comparisons of their pluripotencies. Molecular reproduction and development. 1993; 36 (2): 148-158. https://doi.org/10.1002/mrd.1080360205 Google Scholar

35. Ungkanont A, Mongkonsritrakoon W, Jootar S and Srichaikul T. Allogeneic stem cell transplantation in a patient with refractory burkitt's lymphoma using non-myeloablative conditioning regimen. Bone marrow transplantation. $2000 ; 26$ (12): $1351-1354$. https://doi.org/10.1038/sj.bmt.1702730 Google Scholar

36. ISO. International organization for standardization 14971: [http://www.Iso.Org/iso/iso catalogue.Htm]. 2007.

37. Nguyen PK, Rhee J-W and Wu JC. Adult stem cell therapy and heart failure, 2000 to 2016: A systematic review. JAMA cardiology. 2016; 1 (7): 831-841. https://doi.org/10.1001/jamacardio.2016.2225 Google Scholar

38. Prowse AB, Chong F, Gray PP and Munro TP. Stem cell integrins: Implications for ex-vivo culture and cellular therapies. Stem cell research. 2011; 6 (1): 1-12. https://doi.org/10.1016/j.scr.2010.09.005 Google Scholar

39. de Paula S, Vitola AS, Greggio S, de Paula D, Mello PB, et al. Hemispheric brain injury and behavioral deficits induced by severe neonatal hypoxia-ischemia in rats are not attenuated by intravenous administration of human umbilical cord blood cells. Pediatric research. 2009; 65 (6): 631-635. https://doi.org/10.1203/PDR.obo13e31819ed5c8 Google Scholar

40. Smith AG, Heath JK, Donaldson DD, Wong GG, Moreau J, et al. Inhibition of pluripotential embryonic stem cell differentiation by purified polypeptides. Nature. 1998; 336 (6200): 688-690. https://doi.org/10.1038/336688ao Google Scholar

41. ISO/IEC. International organization for standardization and international electrotechnical commission: Guide 51:[http://www.Iso.Org/iso/iso catalogue.Htm]. 1999. Google Scholar

42. ICH. The international council for harmonisation q9: Quality risk management. [http://www.Ich.Org/products/guidelines.Html]. 2020.

43. EMEA/CHMP. Guideline on risk management systems for medical products for human use, emea/chmp/96268/2005. [http://www.Ema.Europa.Eu]. 2005.

44. Herberts CA, Kwa MS and Hermsen HP. Risk factors in the development of stem cell therapy. Journal of translational medicine. 2011; 9 (1): 29. https://doi.org/10.1186/1479-5876-9-29 Google Scholar

45. Lanza R and Rosenthal N. The stem cell challenge. Scientific American. 2004; 290 (6): 92-99. https://www.jstor.org/stable/26o47759 Google Scholar

46. Freitag J, Bates D, Boyd R, Shah K, Barnard A, et al. Mesenchymal stem cell therapy in the treatment of osteoarthritis: Reparative pathways, safety and efficacy-a review. BMC musculoskeletal disorders. 2016; 17 (1): 230. https://doi.org/10.1186/s12891-016-1085-9 Google Scholar

47. Koga H, Engebretsen L, Brinchmann JE, Muneta T and Sekiya I. Mesenchymal stem cell-based therapy for cartilage repair: A review. Knee Surgery, Sports Traumatology, Arthroscopy. 2009; 17 (11): 1289-1297. https://doi.org/10.1007/s00167-009-0782-4 Google Scholar

48. Martínez-Garza D, Cantú-Rodríguez O, Jaime-Pérez J, Gutiérrez-Aguirre C, Góngora-Rivera J, et al. Current state and perspectives of stem cell therapy for stroke. Medicina Universitaria. 2016; 18 (72): 169-180. https://doi.org/10.1016/j.rmu.2016.07.005 Google Scholar

49. Lindvall $O$, Kokaia $Z$ and Martinez-Serrano A. Stem cell therapy for human neurodegenerative disorders-how to make it work. Nature medicine. 2004; 10 (7): S42-S50. https://doi.org/10.1038/nmlo64 Google Scholar

50. Langhome P, Bernhardt J. Kwakkel G. Stroke rehabilitation. Lancet. 2011; 377 (9778): 1693-1702. Google Scholar

51. Seo B-M, Miura M, Gronthos S, Bartold PM, Batouli S, et al. Investigation of multipotent postnatal stem cells from human periodontal ligament. The Lancet. 2004; 364 (9429): 149-155. https://doi.org/10.1016/So140-6736(04)16627-0 Google Scholar

52. Ramseier CA, Abramson ZR, Jin Q and Giannobile WV. Gene therapeutics for periodontal regenerative medicine. Dental Clinics. 2006; 50 (2): 245-263. https://doi.org/10.1016/j.cden.2005.12.001 Google Scholar

53. Shi S, Bartold P, Miura M, Seo B, Robey P, et al. The efficacy of mesenchymal stem cells to regenerate and repair dental structures. Orthodontics \& craniofacial research. 2005; 8 (3): 191-199. https://doi.org/10.1111/j.1601-6343.2005.00331.x Google Scholar

54. Iohara K, Nakashima M, Ito M, Ishikawa M, Nakasima A, et al. Dentin regeneration by dental pulp stem cell therapy with recombinant human bone morphogenetic protein 2. Journal of dental research. 2004; 83 (8): 590-595. https://doi.org/10.1177\%2F154405910408300802 Google Scholar

55. Hu B, Unda F, Bopp-Kuchler S, Jimenez L, Wang X, et al. Bone marrow cells can give rise to ameloblast-like cells. Journal of dental research. 2006; 85 (5): 416-421. https://doi.org/10.1177\%2F154405910608500504 Google Scholar

56. Liu Y, Liu W, Hu C, Xue Z, Wang G, et al. Mir-17 modulates osteogenic differentiation through a coherent feed-forward loop in mesenchymal stem cells isolated from periodontal ligaments of patients with periodontitis. Stem cells. $2011 ; 29$ (11): $1804-1816$. https://doi.org/10.1002/stem.728 Google Scholar 